\title{
Flow-induced crystallization of propylene/ethylene random copolymers
}

\author{
Jan-Willem Housmans • Gerrit W. M. Peters • \\ Han E. H. Meijer
}

Rheological Analysis of Polymers/Special Chapter

(C) The Author(s) 2009. This article is published with open access at Springerlink.com

\begin{abstract}
The influence of the co-monomer content and processing conditions on the crystallization kinetics of propylene/ethylene $(\mathrm{P} / \mathrm{E})$ random copolymers is studied using DSC and rheometry. The presence of ethylene lowers the melting and crystallization temperature compared to pure polypropylene, and the quiescent crystallization rate, $\dot{X}$, increases at equal nominal undercooling, because both the crystal growth rate, $G$, and number of nuclei, $N$, increases. The effect of flow on the kinetics of crystallization decreases with the ethylene content. Still, different regimes of flow-induced crystallization are observed, but their size and the position of the transitions between them depend on the ethylene content, and can be expressed in terms of the level of molecular orientation, molecular stretch, and crystallization capacity of the system.
\end{abstract}

Keywords Random co-polymers .

Flow-induced crystallization · Polypropylene ·

Flow regimes · Rheology

\section{Introduction}

Properties of polymer products depend on the morphology distribution within the product, which itself depends on both the molecular properties of the polymer used and the processing conditions applied during fabrication. Not only

J.-W. Housmans · G. W. M. Peters ( $₫)$ · H. E. H. Meijer Materials Technology, Eindhoven University of Technology, P. O. Box 513, 5600MB Eindhoven, The Netherlands e-mail: g.w.m.peters@tue.nl

J.-W. Housmans

The Dutch Polymer Institute (DPI), P.O. Box 902,

5600AX Eindhoven, The Netherlands mechanical properties depend on crystal structures [1-3], but also properties, like dimensional stability [4] and transparency [5]. In production processes like injection molding, film blowing, and fiber spinning the polymer is subjected to high pressures and speeds, and it is cooled from temperatures well above its melting point to room temperature within seconds. Due to the complex geometries of the molds and extruder dies, the flow history has a complex nature; the material experiences both shear and elongational flow. The effect of shear deformation on the crystallization kinetics and structure development of semi-crystalline polymers has gained a lot of interest in the last decade, see for example [6-14] and references therein. It is now well known that the flow field applied accelerates the crystallization process, alters the morphology; the effect of shear rate is more pronounced than that of the shear time. The importance of the high molecular weight tail on the formation of oriented, anisotropic structures was stressed $[6,11,12]$.

Van Meerveld et al. [15] proposed a rheological classification of different flow regimes, i.e., regimes leading to different types of crystalline morphologies, derived from molecular-based rheology and rubber elasticity theory. The transitions between the different flow regimes and the associated physical processes governing the flow-induced crystallization (FIC) processes are defined by the critical values of the Deborah numbers $(D e)$ related to the molecular orientation $\left(D e_{\mathrm{rep}}\right)$ and molecular stretch $\left(D e_{\mathrm{s}}\right)$. An extensive evaluation of experiments reported in the literature illustrates that the transition, from just an enhanced nucleation rate of spherulites toward the development of fibrillar structures, correlates with the transition from chain segment orientation to chain stretch applied at least to the high molecular weight chains in the melt.

Polymers are often modified to improve their performance. The changes are implemented on (a) a molecular 
level and/or (b) a microscopic level. In the first case, the polymer chain itself is modified or another material is added and dissolved, while in the latter situation, particles or a phase separated second polymer are added. These alterations to the material have a strong influence on the polymer's FIC behavior.

Several researchers studied case (b), investigating experimentally the particle-morphology-properties relationship [2, 16-20]. The presence of particles leads to strong molecular orientation throughout the complete sample caused by a 'shear amplification effect' between the particles and sometimes an improved impact resistance. Numerical work on particle-filled viscoelastic systems showed that the presence of particles results in the occurrence of regions of high molecular stretch between the layers of particles and regions shielded by the particles inside the layers [21] giving rise to anisotropic flowinduced structures. Another additive is the family of nucleating agents and they are often blended with polymers to decrease conversion cycle times [22]. Crystallization on heterogeneous nuclei leads to the formation of smaller crystal structures which improves the optical and mechanical properties of the materials. An example of such an additive is based on sorbitol (DMDBS), which already in relatively small amounts $(\sim 0.2 \mathrm{wt} \%)$ enhances the clarity, and gives rise to an increase in yield stress of isotactic polypropylene (iPP) [5, 23]. The effect of flow on crystallization of iPP/DMDBS blends was studied by Balzano et al. [24, 25]. Recently, even much more effective and selective nucleating agents based on 1,3,5-benzene tricarboxylic acid were developed with which the same effects are obtained for concentrations as low as $0.02 \mathrm{wt} \%$ $[26,27]$. This family of organic compounds is thermally stable and some members form the iPP $\beta$-polymorph which exhibits a higher impact toughness than the most common $\alpha$-form [28].

Examples of chain modifications (case (a)) are long chain branching (J. F. Vega, personal communication) and copolymerization with other monomers creating, e.g., random or blockcopolymers.
In this experimental study, the focus is on the effect of random copolymerization of PP with ethylene on FIC. Copolymerization of polypropylene with a small amount of ethylene is an appropriate way to improve both the optical and certain mechanical properties (low temperature brittleness) [29-31]. First, the four grades used are characterized using differential scanning calorimetry (DSC) and rheometry. Next short term shear experiments are performed at equal nominal undercooling, and the flow effects are quantified with a characteristic time scale. Finally, the effect of copolymerization on the rheological classification is investigated. Different regimes are observed and the transitions between regimes are specific for every polymer.

\section{Experimental}

\section{Materials}

Materials used are an isotactic polypropylene (iPP, $\mathrm{HD} 234 \mathrm{CF}$, Borealis) and three propylene/ethylene (P/E) random copolymers (P/E RACO, RD204CF, RD226CF, and RD208CF, Borealis) with different ethylene contents. All four grades have a weight average molecular mass $M_{\mathrm{w}} \sim 310 \mathrm{~kg} \mathrm{~mol}^{-1}$ and a polydispersity $M_{\mathrm{w}} / M_{\mathrm{n}} \sim 3.4$ [29]. Molecular and other physical properties are listed in Table 1. RACO2 differs from the iPP and the other two RACO's in that it contains some additives not present in the others like a slip agent to reduce the friction coefficient (for post-processing steps in film applications) and a synthetic silica anti-blocking aid to reduce the adhesion between the film layers $[32,33]$. The anti-blocking aid consists of both spherical and plate-like particles ranging in size between $100 \mathrm{~nm}$ up to $10 \mu \mathrm{m}$. We kept this material in our series of RACO's because it shows that slight modifications of the composition of a polymer (case (b), 1), with no influence on the rheological behavior and expected behavior for quiescent crystallization, can have a large effect on the FIC behavior.

Table 1 Basic characteristics of the material grades from literature [29]

\begin{tabular}{|c|c|c|c|c|c|c|c|c|}
\hline \multirow[t]{2}{*}{ Name } & \multirow[t]{2}{*}{ Grade } & \multicolumn{2}{|c|}{ Ethylene content } & \multirow[t]{2}{*}{$T_{\mathrm{m}} /{ }^{\circ} \mathrm{C}[29]$} & \multirow[t]{2}{*}{$X_{\mathrm{c}} / \%[29]$} & \multirow[t]{2}{*}{$T_{\mathrm{m}} /{ }^{\circ} \mathrm{C}$} & \multirow[t]{2}{*}{$X_{\mathrm{c}} / \%$} & \multirow[t]{2}{*}{$T_{\mathrm{c}} /{ }^{\circ} \mathrm{C}$} \\
\hline & & $\begin{array}{l}\text { FTIR/ } \\
\text { wt } \%\end{array}$ & $\begin{array}{l}\text { NMR/ } \\
\text { mol\% }\end{array}$ & & & & & \\
\hline PP & HD234CF & 0 & 0 & 164 & 49.5 & 159 (163) & 48.3 & 110 \\
\hline RACO1 & RD204CF & 2.2 & 3.4 & 153 & 41.3 & 147 (153) & 42.3 & 105 \\
\hline RACO2 & RD226CF & 3.4 & 5.2 & 145 & 36.3 & $140(146)$ & 36.8 & 99 \\
\hline RACO3 & RD208CF & 4.9 & 7.3 & 139 & 33.9 & $138(145)$ & 34.4 & 98 \\
\hline
\end{tabular}

$T_{\mathrm{m}}, X_{\mathrm{c}}$, and $T_{\mathrm{c}}$ are determined on the provided materials. The $T_{\mathrm{m}}$ values between brackets are explained in section "DSC" 
Differential scanning calorimetry (DSC)

The melting temperature $\left(T_{\mathrm{m}}\right)$, melting enthalpy $\left(\Delta H_{\mathrm{m}}\right)$ and crystallization temperature $\left(T_{\mathrm{c}}\right)$ were determined on a Mettler Toledo DSC (DSC823e) using a heating and

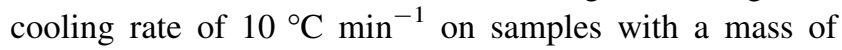
$5 \pm 0.5 \mathrm{mg}$. A second heating cycle is performed to have a homogeneous sample distribution in the pan from which $T_{\mathrm{m}}$ and $\Delta H_{\mathrm{m}}$ are obtained. Crystallinity is determined using $X_{\mathrm{c}}=\Delta H_{\mathrm{m}} / \Delta H_{\mathrm{m} 0}$ with the melting enthalpy for a $100 \%$ crystalline material, $\Delta H_{\mathrm{m} 0}=209 \mathrm{~J} \mathrm{~g}^{-1}$ [34].

Rheological properties in the melt state

A Rheometrics ARES rheometer was used with a plateplate geometry, diameter $25 \mathrm{~mm}$, for small amplitude oscillatory shear measurements. The characteristic rheological properties (storage and loss modulus, $G^{\prime}$ and $G^{\prime \prime}$, and loss angle, $\delta$ ) were obtained over a broad range of temperatures (from 145 to $250{ }^{\circ} \mathrm{C}$ ) and angular frequencies, $\omega$ (from 0.01 to $100 \mathrm{rad} \mathrm{s}^{-1}$ ). The lower limit of $\omega$ for the lowest temperature was $0.1 \mathrm{rad} \mathrm{s}^{-1}$ to avoid the changes due to crystallization. To determine the rheological properties in the linear viscoelastic regime, the strain applied was determined from strain sweeps and set to $5 \%$ for all measurements. The experiments were performed in a nitrogen environment to avoid degradation of the material. Time-temperature superposition has been applied to obtain mastercurves at a reference temperature of $220{ }^{\circ} \mathrm{C}$.

Flow-induced crystallization experiments

The crystallization kinetics was followed using rheological experiments. A relatively small plate-plate geometry of $8 \mathrm{~mm}$ was used to avoid transducer instabilities caused by stiffening of the material. Isothermal temperatures were chosen such that the undercooling, which is the driving force for crystallization, was equal for all four materials. Undercooling is normally defined as $\Delta T=T_{\mathrm{m} 0}-T_{\text {exp }}$, with $T_{\mathrm{m} 0}$ the equilibrium melting temperature and $T_{\exp }$ the isothermal crystallization temperature at which the experiment is performed. For the polymer grades used, $T_{\mathrm{m} 0}$ is not known and the determination of $T_{\mathrm{m} 0}$ is a lengthy and precise task, as shortly discussed in the next section. Therefore, we define undercooling as $\Delta T=T_{\mathrm{m}}-T_{\text {exp }}$, where $T_{\mathrm{m}}$ is the nominal melting temperature determined from DSC, see Table 1. For the homopolymer $T_{\exp }$ was set to $138{ }^{\circ} \mathrm{C}$ and for the $\mathrm{P} / \mathrm{E}$ RACO the temperature was determined accordingly, i.e., to get the same $\Delta T$. The experimental procedure is as follows:

- Samples were molten at a temperature of $230{ }^{\circ} \mathrm{C}$ for $10 \mathrm{~min}$ to remove any history before the start of the test.
- Subsequently, the samples were cooled to the desired crystallization temperature with a controlled cooling rate of $15^{\circ} \mathrm{C} \min ^{-1}$ to avoid any undershoot. The gap was adjusted continuously to compensate for thermal expansion (shrinkage) of the samples.

- Oscillatory tests using an angular frequency of $5 \mathrm{rad} \mathrm{s}^{-1}$ and a strain of $0.5 \%$ were performed to monitor the evolution of $G^{\prime}, G^{\prime \prime}$, and $\delta$ in time.

For the short-term FIC experiments, a shear flow for a certain shear time, $t_{\mathrm{s}}$, was applied prior to the third step. The shear rate values, $\dot{\gamma}$, varied between 3 and $60 \mathrm{~s}^{-1}$ and the total strain, $\gamma$, was kept constant at 60 strain units.

The ARES rheometer has an intrinsic problem which, in principle, does not allow combining a pre-shear and an oscillatory flow. The oscillation is performed around the origin, a fixed angular position of the plate. The pre-shear will move the plate away from this origin and consequently, when the dynamic measurement is started, the plate is automatically brought back fast to its origin, straining the material more. To overcome this problem, the following procedure is applied: at the experimental temperature, before inserting the material, so with empty plates, shear is applied with the same conditions as for the short-term shear flow, but in opposite flow direction. Subsequently, the material is inserted and the experimental procedure as mentioned above is started. As a consequence, when the pre-shear is applied on the material, the plate moves back to its origin and the material experiences no extra straining at the start of the dynamic measurement.

Figure 1 shows flow-induced crystallization experiments on an iPP grade (Borealis HD120MO, J. F. Vega, personal communication, used in Ref. [35]) that follow the above-mentioned procedure $\left(T_{\exp }=135{ }^{\circ} \mathrm{C}\right)$. The figure is illustrative for the results expected. The storage modulus, $G^{\prime}(t)$, evolves with the growing crystallites in the melt, since it is a function of degree of space filling, $\varphi$. When flow is applied, the two main observations are:

(1) Curve 2: An acceleration of the crystallization process, the modulus curve shifts to lower times. The shape is similar to that of the quiescent experiment.

(2) Curve 3: For longer flow times, the modulus rise shifts to lower times, but now its shape changes and the slope decreases.

The kinetics of degree of space filling is usually described by the Avrami equation [36, 37]:

$\phi=1-\exp \left(-C t^{n}\right)$

where $C$ is the overall rate of crystallization and $n$ the Avrami exponent, which reflects the crystal dimensionality 


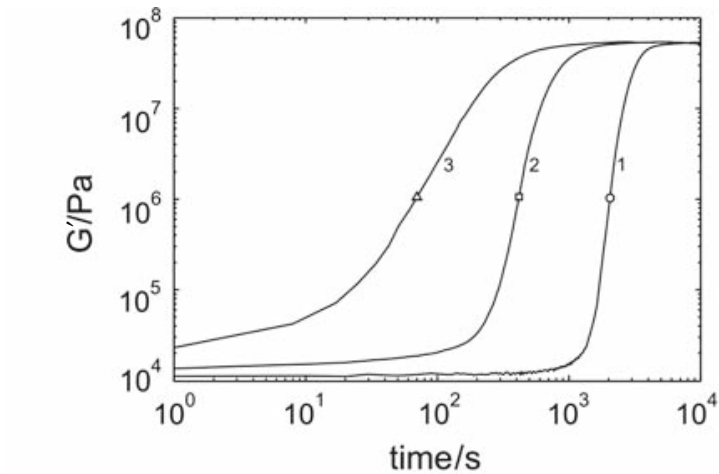

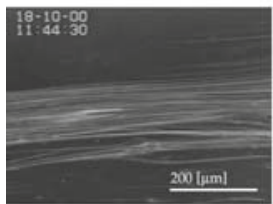

(3)

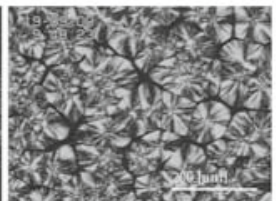

(2)

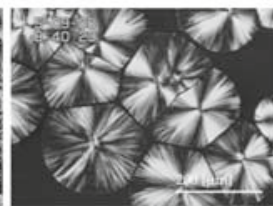

(1)
Fig. 1 Evolution of the storage modulus during crystallization of iPP $\mathrm{HD} 120 \mathrm{MO}$ at $T_{\exp }=135{ }^{\circ} \mathrm{C}$, measured under quiescent conditions (open circle, 1) and after shearing at $\dot{\gamma}=60 \mathrm{~s}^{-1}$ for $t_{s}=1 \mathrm{~s}$ (open square, 2) and $t_{\mathrm{s}}=6 \mathrm{~s}$ (open triangle, 3). Optical micrographs indicate the characteristic morphology for the three crystallization experiments [40]

and the type of nucleation (pre-determined or sporadic) [38]. When the nucleation is heterogeneous and the crystal growth rate, $G$, is constant, the $n$ values of 1,2 , and 3 correspond to a crystal geometry of rods (1-dimensional, 1D), disks (2-dimensional, 2D) and spheres (3-dimensional, 3D), respectively. For sporadic nucleation, the $n$ values of 2, 3, and 4 correspond to the crystal geometry of rods, disks, and spheres [37, 39]. For the change of the modulus it can be derived that:

$\frac{\mathrm{d} G^{\prime}}{\mathrm{d} t}=\frac{\mathrm{d} G^{\prime}}{\mathrm{d} \phi} \frac{\mathrm{d} \phi}{\mathrm{d} t}$

in which $\mathrm{d} \varphi / \mathrm{d} t$ is given by (using Eq. 1):

$\frac{\mathrm{d} \phi}{\mathrm{d} t}=C n t^{n-1} \exp \left(-C t^{n}\right)$

From Eqs. 1 and 3 it can be derived that to achieve a shift over the time axis to lower times, without changing the shape of the curve (curve 2), the Avrami exponent, $n$, has to be the same, and only the overall rate of crystallization, $C$, increases. Hence, for a shift and a change in slope (curve 3), $C$ increases and $n$ decreases. Under quiescent conditions in the temperature range applied, no sporadic nucleation occurs and the number of nuclei, $N$, is constant. Crystal lamellae grow with a constant growth rate, $G$, in all directions, thus a 3D growth, from these nuclei forming spherulites (Fig. 1, micrograph 1 [40]). In that case, $n=3$ and $C=4 / 3 \pi N G^{3}$ [37, 38, 41, 42]. When flow, applied for a short time, only leads to a shift in modulus (curve 2), only $C$ increases and $n$ stays the same and we expect no sporadic nucleation. This implies that the same type of morphology is formed as in the quiescent case (spherulites), but with a higher number density $N$, since $C$ increases and the growth rate $G$ is unaltered [42] (Fig. 1, micrograph 2 [40]). For longer flow times, where a change in the slope is observed (curve 3), $n$ decreases. Oriented, shish-kebabs are formed by crystalline lamellae growing in two dimensions (2D) off fibrillar nuclei (Fig. 1, micrograph 3 [40]), for which it can be derived, that $n=2$ and $C=\pi N L G^{2}$, with $L$, the total length of the shishes [37, 41]. Also in this situation, no sporadic nucleation is expected. Of course, not only fibrillar structures are formed, spherulites will grow as well, and thus $2<n<3$. For the experiments shown in Fig. 1, the resulting morphologies were confirmed using optical microscopy $(\mathrm{OM})$ and wide-angle X-ray diffraction (WAXD) (D. G. Hristova, personal communication, used in Ref. [35]). To summarize the above, three morphology types are distinguished as

(1) Quiescent crystallization: Spherulites are formed by crystalline lamellae growing in three dimensions off point-like nuclei, whose number density depends on the temperature.

(2) Shift of modulus curve: The number density of pointlike nuclei increases with the strain rate. This leads to a more fine grained but still spherulitic morphology.

(3) Shift and shape change: Shish-kebabs are formed by crystalline lamellae growing in two dimensions off fibrillar nuclei, whose number density and length increases with strain rate.

Four flow regimes, based on the rheology of the polymer, are defined by van Meerveld et al. [15]. The transitions between these regimes are defined by critical values of the Deborah number, De $(\tau / t)$ ) or Weissenberg number, $W i(=\dot{\gamma} \tau)$, related to molecular orientation and molecular stretch. Both orientation and stretch are characterized by a time scale: the reptation time, $\tau_{\text {rep }}$, and the stretch relaxation time or Rouse time, $\tau_{\mathrm{s}}$, respectively. In regime I, for $D e_{\text {rep }}$ and $D e_{\mathrm{s}}<1$, the chains are at equilibrium. The transition to regime II corresponds to orientation of the contour path $\left(D e_{\text {rep }}>1, D e_{\mathrm{s}}<1\right)$. The onset of chain stretching $\left(D e_{\text {rep }}>1, D e_{\mathrm{s}}>1\right)$ marks regime III, and in the fourth and final regime, the chains are strongly stretched and deviate from the Gaussian configuration caused by rotational isomerization. The analysis of FIC experiments reported in literature indicated that the high molecular weight (HMW) chains dictate the FIC dynamics $[6,12]$. Furthermore, the number density of spherulites increases in regime II $\left(D e_{\text {rep }}>1, D e_{\mathrm{s}}<1-10\right)$ and the shish-kebab morphology develops for $D e_{\mathrm{s}}>1-10$ based on $\tau_{\mathrm{s}}$ of the longest chains. Characterization of the melt 
provides the relaxation time spectrum, i.e., $\tau_{\text {rep }}$ from which $\tau_{\mathrm{s}}$ can be estimated as

$\tau_{\mathrm{s}}=\tau_{\text {rep }} / 3 Z$

with $Z=M_{\mathrm{w}} / M_{\mathrm{e}}$ is the number of entanglements per chain and $M_{\mathrm{e}}$ is the weight average molecular weight between entanglements, being $5,200 \mathrm{~g} \mathrm{~mol}^{-1}$ for iPP [43]. The classification is only valid for short time shear. Although it gives a clear indication in which flow regime experiments are performed and whether fibrillar morphologies will develop or not, the flow time is not specifically included. Nevertheless, for regime III/IV, it is stated that the flow time, $t_{\mathrm{s}}$, has to be sufficiently long in order to fulfill the condition $\lambda>\lambda^{*}(T)$, i.e., the molecular stretch ratio $\lambda$ has to be larger than a certain critical value $\lambda *(T)$, marking the transition between weak and strong stretching conditions. Moreover, it is expected that this critical value has to be maintained long enough to cause significant shish growth. On the other hand, when shearing in regime II for a too long time, the rheology of the material will change, i.e., due to nucleation physical crosslinking will occur which increases the relaxation times and thus the Deborah number, and, therefore the flow regime changes to type III/IV. This self enhancing effect is described and modeled by Zuidema et al. [44] and Peters et al. [45]. A recent model that takes these effects into account is given by Custodio [46].

To clarify the relation between the flow regimes and the morphology types and to show the effect of shear rate $(\dot{\gamma})$, shear time $\left(t_{\mathrm{s}}\right)$, and shear strain $\left(\gamma=\dot{\gamma} t_{\mathrm{s}}\right)$ on the crystallization behavior of the polymers, a schematic picture is presented, see Fig. 2. A common way to characterize the crystallization kinetics is to define a time, $t$, characteristic for the process, e.g., the induction time $\left(t_{\mathrm{i}}\right)$ or the half-time of crystallization $\left(t_{1 / 2}\right)$, and to normalize this with the characteristic time of the quiescent case $\left(t_{\mathrm{Q}}\right)$ [47, 48]. According to the classification, the transitions from flow

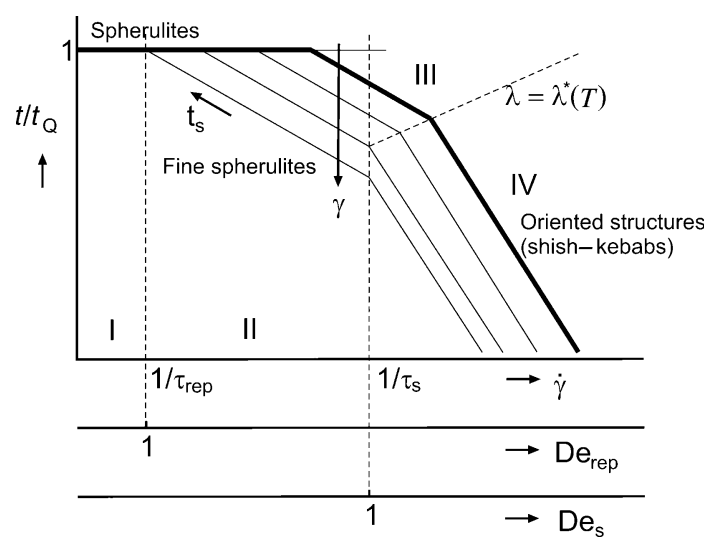

Fig. 2 Schematic representation of the flow regimes and morphology types. See the text for explanation regime I to II and flow regime II to III are marked by $D e_{\text {rep }}=1$ and $D e_{\mathrm{s}}=1$, corresponding to a shear rate value of $1 / \tau_{\text {rep }}$ and $1 / \tau_{\mathrm{s}}$, respectively. These transitions are included in Fig. 2 as the two vertical dashed lines. First, let us consider FIC experiments with a constant level of applied strain (bold line, Fig. 2). At low values of the shear rate, flow does not influence the crystallization behavior, i.e., the material crystallizes as in quiescent conditions, represented by the horizontal line at $t / t_{\mathrm{Q}}=1$ (morphology type 1). For higher values of $\dot{\gamma}$, the crystallization process is accelerated and $t / t_{\mathrm{Q}}$ becomes smaller than 1 . Shear rate is more effective than shear time in accelerating polymer crystallization, and hence for increasing shear rates $t / t_{\mathrm{Q}}$ decreases. The shape (slope) of the modulus curve versus time is the same compared to the quiescent experiment, which means that the crystallization kinetics are unaltered. The decrease in crystallization time is associated with an increase of the number of point-like nuclei (morphology type 2). With a further increase of $\dot{\gamma}$, a change in the slope of the $G^{\prime}$-evolution curve is observed, indicative for a change in the crystallization kinetics, and the crystallization process is even faster. It is related to the transition from isotropic spherulitic crystals to oriented shish kebab structures (morphology type 3). Consequently, the slope of $t / t_{\mathrm{Q}}$ becomes steeper. As can be seen in the schematic picture, the transitions in $t / t_{\mathrm{Q}}$ fall within flow regime II and flow regime III. However, they do not necessarily coincide with the shear rate values of $1 / \tau_{\text {rep }}$ and $1 / \tau_{\text {s }}$, i.e., the transitions from flow regime I to II and flow regime II to III, respectively. When the shear strain level is increased, the two transition points in the $t / t_{\mathrm{Q}}$ curve move to lower shear rates, eventually coinciding with the transitions between the different flow regimes. This shows the importance of flow time: flow has to be applied for a sufficiently long time in order to orient or stretch the polymer chains enough to observe an effect on the crystallization behavior and final morphology, which is in line with the conclusions of Van Meerveld et al. [15]. The transition that still needs explanation is from flow regime III to IV, the 'weak' and 'strong' stretching regime, respectively. In flow regime III, the chains are stretched, but still keep their Gaussian configuration. For $\lambda>\lambda *(T)$ the chain configuration becomes non-Gaussian and the amount of rotational isomerization (RI) is large (regime IV). Based on the analysis of FIC experiments reported in literature it was concluded that the shish-kebab morphology develops when the HMW chains are subjected to the condition $D e_{\mathrm{s}}>1$ for a sufficiently long time in order to fulfill the condition $\lambda>\lambda^{*}(T)$ [15]. Hence, in the schematic picture (Fig. 2), the transition from flow regime III to IV occurs for $t / t_{\mathrm{Q}}$ when the second change in slope is observed, i.e., it coincides with the onset of morphology type 3. Here, the evolution of $G^{\prime}$ shows a change in slope, i.e., a change in 
the crystallization kinetics, and the shish-kebab crystal structure forms. In the schematic picture, the direction of the line that marks the transition from III to IV is arbitrarily chosen.

\section{Equilibrium melting point, $T_{\mathrm{m} 0}$}

Usually, two extrapolation methods are used to determine the equilibrium melting point, $T_{\mathrm{m} 0}$, the Gibbs-Thomson (GT) [49] and the Hoffman-Weeks (HW) [50] method. As a result of a finite crystal thickness, $l, T_{\mathrm{m}}$ is depressed below that of an infinite size crystal which is expressed in the GT equation:

$$
T_{\mathrm{m}}=T_{\mathrm{m} 0}\left(1-\frac{2 \sigma_{\mathrm{e}}}{l \Delta H_{\mathrm{f}}}\right)
$$

where $\sigma_{\mathrm{e}}$ is the surface free energy of the crystal plane normal to the thickness direction and $\Delta H_{\mathrm{f}}$ the heat of fusion. From Eq. 5, it can be seen that $T_{\mathrm{m} 0}$ can be estimated by extrapolating $T_{\mathrm{m}}$ versus $1 / l$ data to infinite thickness. This method requires X-ray scattering techniques to determine the thickness of the crystals and a method (e.g., DSC) to measure the melting point of these lamellae.

The HW procedure correlates directly the temperature of crystallization $T_{c}$ to the melting temperature $T_{m}$ of the structures formed during subsequent melting (Eq. 6).

$T_{m}=T_{m 0}\left(1-\frac{1}{\gamma}\right)+\frac{T_{c}}{\gamma}$

The parameter $\gamma=l / l_{\mathrm{i}}$ accounts for isothermal lamellar thickening after formation of an initial crystal with thickness $l_{\mathrm{i}}$. Thicker crystals are usually formed when a polymer crystallizes at higher temperatures, resulting in a higher $T_{\mathrm{m}}$. $T_{\mathrm{m} 0}$ can be determined by linear extrapolation of $T_{\mathrm{m}}$ as a function of $T_{\mathrm{c}}$ to the equilibrium line $T_{\mathrm{m}}=T_{\mathrm{c}}$. This method only requires a DSC device which makes it easy to obtain the necessary data.

In both methods, lamellar thickening plays an important role. When the lamellar thickness for GT is determined at room temperature, an increase of the crystal height can occur during melting. A correct extrapolation is only possible for the HW method when the thickening coefficient is independent of the crystallization temperature, i.e., only samples crystallized at different temperatures, but with the same value for $\gamma$, can be used to correctly determine $T_{\mathrm{m} 0}$ [51].

Both methods were applied by [52] to evaluate the discrepancies between two groups of $T_{\mathrm{m} 0}$ values reported for iPP, one group around $187{ }^{\circ} \mathrm{C}$ and the other around $210^{\circ} \mathrm{C}$. They found for the GT method an equilibrium melting temperature of around $186{ }^{\circ} \mathrm{C}$. The result determined with the HW method was however greatly influenced by the crystallization time. Where impinged, big spherulites ( long crystallization times) gave a value of $210{ }^{\circ} \mathrm{C}, T_{\mathrm{m} 0}$ determined from small spherulites, crystallized for a short time, was around $188{ }^{\circ} \mathrm{C}$. According to Mezghani et al. [52], the most accurate result with the HW procedure would be obtained when $T_{\mathrm{m}}$ of very small, newly initiated spherulites could be measured, because the polymer continues to crystallize during heating.

In a subsequent paper on P/E RACO's with similar molecular weights, a significant decrease of $T_{\mathrm{m} 0}$ was observed for an increase in ethylene content $\left(\sim 5{ }^{\circ} \mathrm{C} \mathrm{mol} \%{ }^{-1}\right)$ using the HW method [53]. In a crystallization study on fractionated P/E RACO's, it was found that the equilibrium melting point was lowered by approximately $2.3{ }^{\circ} \mathrm{C} \mathrm{mol} \%^{-1}$ [54]. These observations imply for RACO3 with an ethylene content of $7.3 \mathrm{wt} \%$ a significant difference in $T_{\mathrm{m} 0}$, i.e., $150{ }^{\circ} \mathrm{C}$ [53] and $170{ }^{\circ} \mathrm{C}$ [54], adapting $T_{\mathrm{m} 0}=187^{\circ} \mathrm{C}$ for the iPP homopolymer. The preference would maybe go to the former, because commercially available polymer grades are used with a comparable molar mass to our materials, where the latter used fractionated samples. The choice for either one would, however, be equally right (or wrong).

As discussed here, determination of the equilibrium melting point is a tedious procedure in which errors can be made easily. It is outside the scope of this study to get exact values. The melting temperatures mentioned in Table 1 show a dependence on ethylene content of $3-3.5{ }^{\circ} \mathrm{C} / \mathrm{mol} \%$ which is of the same order as reported in $[53,54]$. Therefore, we will use the nominal undercooling as mentioned in section "Flow-induced crystallization experiments" to determine $T_{\mathrm{c}, \exp }$.

\section{Results and discussion}

\section{DSC}

The melting temperature $T_{\mathrm{m}}$, the amount of crystallinity $X_{c}$, determined from the melting enthalpy, and the crystallization temperature $T_{\mathrm{c}}$ are given in Table 1. The melting thermograms of all four materials show bimodal melting, see Fig. 3. The $T_{\mathrm{m}}$ values in Table 1 are the values of the low temperature peak which is the most pronounced. The high temperature peak/shoulder values are given in brackets. No influence of the additives in RACO2 is observed, i.e., the results nicely fit the trend that with increasing amount of ethylene, $T_{\mathrm{m}}, X_{\mathrm{c}}$, and $T_{\mathrm{c}}$ decrease. Measurements of Laihonen et al. [54] indicated that the bimodal melting behavior for fractionated P/E RACO's occurs due to recrystallization during heating. At high heating rates the melting behavior of their fractions was unimodal. A slightly lower melting temperature is observed compared to the values of Gahleitner et al. [29], which is 


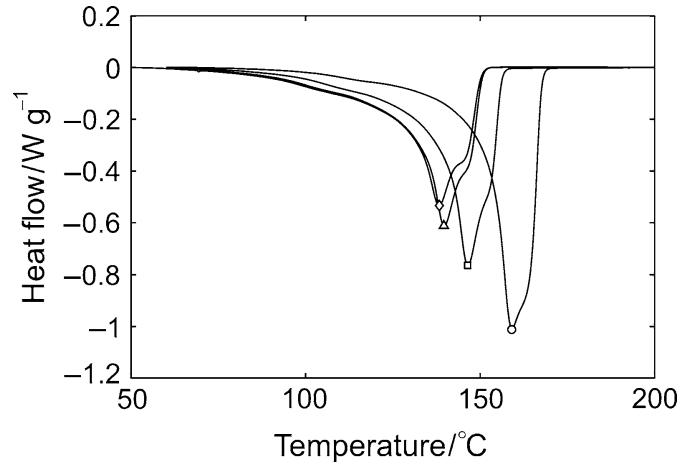

Fig. 3 Melting thermograms of PP (open circle), RACO1 (open square), RACO2 (open triangle) and RACO3 (open diamond)

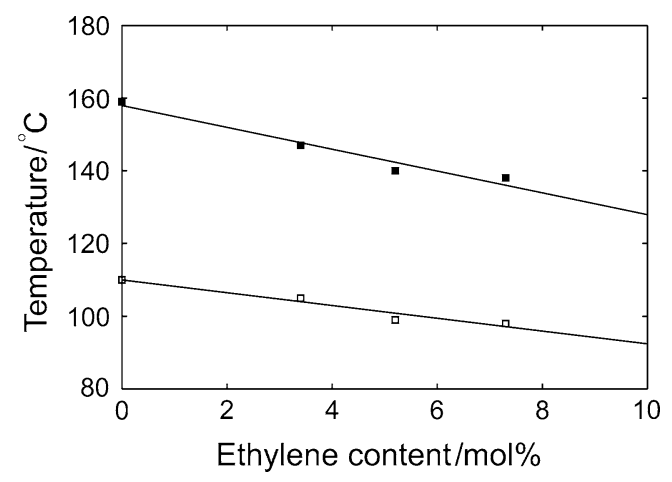

Fig. 4 Melting (filled square) and crystallization (open square) peak temperature as a function of the ethylene content

probably due to the use of a different DSC device and/or a different batch of material. The amount of crystallinity of the samples compares well. Figure 4 shows the decrease of $T_{\mathrm{m}}$ and $T_{\mathrm{c}}$ with ethylene content, which are approximately $3.0{ }^{\circ} \mathrm{C} \mathrm{mol} \%^{-1}$ and $1.8{ }^{\circ} \mathrm{C} \mathrm{mol} \%^{-1}$, respectively. Laihonen et al. [54] reported that both temperatures went down by $3.0^{\circ} \mathrm{C} \mathrm{mol} \%{ }^{-1}$. The small difference in slope for the crystallization temperature is probably due to the use of fractionated samples in [54].

\section{Rheological properties}

The rheological properties at a temperature of $220{ }^{\circ} \mathrm{C}$ for pure iPP and P/E RACO with $7.3 \mathrm{~mol} \%$ are shown in Fig. 5. All materials show very similar behavior in the linear viscoelastic regime. The horizontal and vertical shift factors are listed in Table 2. An Arrhenius temperature dependence is found for the horizontal shift factors $\left(a_{T}\right)$. The value of the activation energy, $E_{\mathrm{a}}$, is (almost) the same for all four materials. The vertical shift factor, $b_{T}$, shows no strong temperature dependence, which is normal behavior for linear polymers. The relaxation time spectrum of the

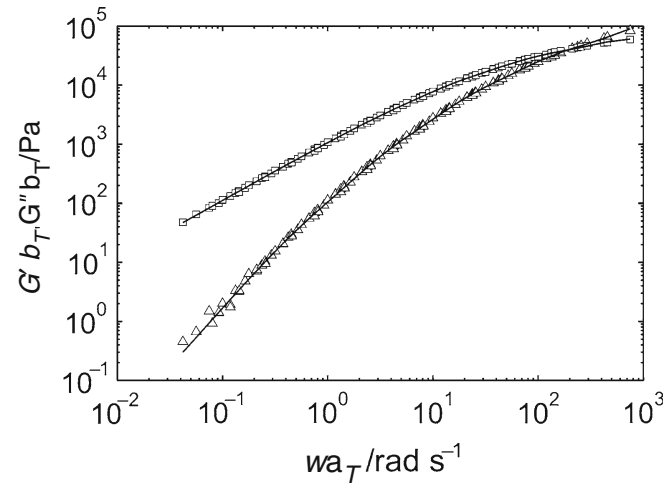

(a)

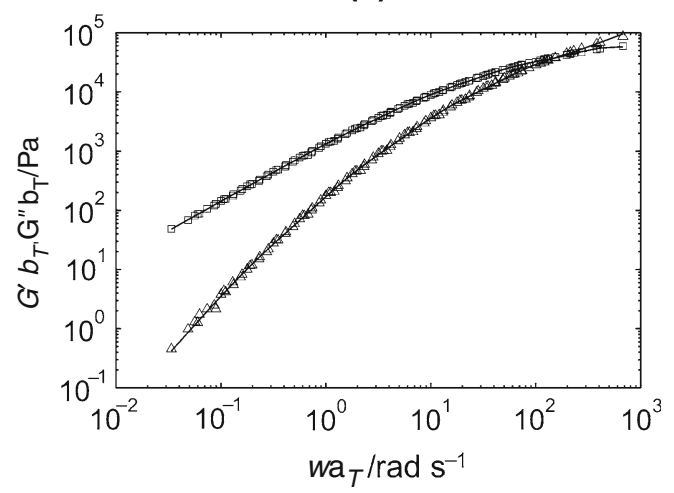

(b)

Fig. 5 Storage (open triangle) and loss (open square) modulus at $T_{\text {ref }}=220{ }^{\circ} \mathrm{C}$ for $\mathbf{a}$ the iPP homopolymer (PP) and $\mathbf{b}$ the P/E RACO with 7.3 wt\% ethylene (RACO3). The lines correspond to a 5 mode Maxwell fit to the moduli

polymers in the melt state (at $220^{\circ} \mathrm{C}$ ) can be calculated from the rheological properties measured. For that purpose, a discrete Maxwell relaxation time spectrum $\left(g_{i}, \tau_{i}\right)$ is used [55]:

$G^{\prime}(\omega)=\sum_{i} g_{i} \frac{\omega^{2} \tau_{i}^{2}}{1+\omega^{2} \tau_{i}^{2}}$

$G^{\prime \prime}(\omega)=\sum_{i} g_{i} \frac{\omega \tau_{i}}{1+\omega^{2} \tau_{i}^{2}}$

The set of relaxation moduli, $g_{i}$, and times, $\tau_{i}$, are given in Table 2 which nicely fit the measured $G^{\prime}$ and $G^{\prime \prime}$ (solid lines in Fig. 5). In Table 3, the values of $\tau_{\text {rep }}^{\text {long }}$ from the discrete relaxation times spectrum for the four materials at $220{ }^{\circ} \mathrm{C}$ are reported, together with the corresponding Rouse time, $\tau_{\mathrm{s}}^{\text {long }}$ (Eq. 4). Also reported here, are the temperature at which the FIC experiments are performed, $T_{\text {exp }}$, the corresponding $a_{T}$, calculated from the Arrhenius relation, and the characteristic relaxation times at the $T_{\text {exp }}$. It is observed that the times at $220{ }^{\circ} \mathrm{C}$ are very similar for the four material grades used, which shows that the viscoelastic behavior is not influenced by the incorporation of ethylene units. 
Table 2 Rheological parameters at $220{ }^{\circ} \mathrm{C}$ for the materials studied: time-temperature shift factors, $a_{T}$ and $b_{T}$, Arrhenius activation energy, $E_{a}$, and Maxwell relaxation spectra, $g_{i}$ and $\tau_{i}$

\begin{tabular}{|c|c|c|c|c|c|}
\hline \multicolumn{3}{|l|}{ iPP HD234CF } & \multicolumn{3}{|c|}{ P/E RACO RD204CF } \\
\hline$T /{ }^{\circ} \mathrm{C}$ & $a_{T}$ & $b_{T}$ & $T /{ }^{\circ} \mathrm{C}$ & $a_{T}$ & $b_{T}$ \\
\hline \multicolumn{6}{|l|}{ Shift factors } \\
\hline 145 & 7.50016 & 0.88649 & 145 & 6.98125 & 0.89018 \\
\hline 160 & 4.54793 & 0.93154 & 160 & 4.00255 & 0.88957 \\
\hline 175 & 2.91501 & 0.95363 & 175 & 2.70305 & 0.92252 \\
\hline 190 & 2.11167 & 0.97134 & 190 & 1.79036 & 0.91121 \\
\hline 205 & 1.42567 & 1.00486 & 205 & 1.29904 & 0.93807 \\
\hline 220 & 1 & 1 & 220 & 1 & 1 \\
\hline 235 & 0.74755 & 1.05951 & 235 & 0.76843 & 0.98564 \\
\hline 250 & 0.66550 & 1.23371 & 250 & 0.58716 & 1.05056 \\
\hline \multicolumn{6}{|l|}{ Arrhenius } \\
\hline$E_{a} / \mathrm{kJ} \mathrm{mol}^{-1}$ & 43.0 & - & $E_{\mathrm{a}} / \mathrm{kJ} \mathrm{mol}^{-1}$ & 42.04 & - \\
\hline$T_{\text {ref }}{ }^{\circ} \mathrm{C}$ & 220 & - & $T_{\mathrm{ref}} /{ }^{\circ} \mathrm{C}$ & 220 & - \\
\hline Mode & $0^{-4} / \mathrm{Pa}$ & $\tau_{i} / \mathrm{s}$ & Mode & $i 0^{-4} / \mathrm{Pa}$ & $\tau_{i} / \mathrm{s}$ \\
\hline
\end{tabular}

Maxwell modes

\begin{tabular}{llllll}
1 & 11.08 & 0.0011 & 1 & 10.53 & 0.0014 \\
2 & 3.38 & 0.0085 & 2 & 3.21 & 0.010 \\
3 & 0.870 & 0.0448 & 3 & 0.817 & 0.057 \\
4 & 0.106 & 0.237 & 4 & 0.097 & 0.316 \\
5 & 0.004 & 1.46 & 5 & 0.004 & 2.07 \\
\hline
\end{tabular}

\begin{tabular}{|c|c|c|c|c|c|}
\hline \multicolumn{3}{|c|}{ P/E RACO RD226CF } & \multicolumn{3}{|c|}{ P/E RACO RD208CF } \\
\hline$T /{ }^{\circ} \mathrm{C}$ & $a_{T}$ & $b_{T}$ & $T /{ }^{\circ} \mathrm{C}$ & $a_{T}$ & $b_{T}$ \\
\hline
\end{tabular}

Shift factors

\begin{tabular}{|c|c|c|c|c|c|}
\hline 145 & 7.11353 & 0.92549 & 145 & 6.76522 & 0.93119 \\
\hline 160 & 4.25546 & 0.95089 & 160 & 4.09919 & 0.95672 \\
\hline 175 & 2.59461 & 0.96162 & 175 & 2.73183 & 0.92839 \\
\hline 190 & 1.86385 & 0.99016 & 190 & 1.97125 & 0.95734 \\
\hline 205 & 1.29624 & 0.98906 & 205 & 1.31445 & 0.97546 \\
\hline 220 & 1 & 1 & 220 & 1 & 1 \\
\hline 235 & 0.67175 & 1.06811 & 235 & 0.59987 & 1.00720 \\
\hline 250 & 0.51710 & 1.10467 & 250 & 0.50280 & 1.03202 \\
\hline \multicolumn{6}{|l|}{ Arrhenius } \\
\hline$E_{a} / \mathrm{kJ} \mathrm{mol}^{-1}$ & 44.70 & - & $E_{a} / \mathrm{kJ} \mathrm{mol}^{-1}$ & 45.19 & - \\
\hline$T_{\text {ref }} /{ }^{\circ} \mathrm{C}$ & 220 & - & $T_{r e f} /{ }^{\circ} \mathrm{C}$ & 220 & - \\
\hline . & ${ }^{4} / \mathrm{Pa}$ & $\tau_{i} / \mathrm{s}$ & Mode & $10^{-4} / \mathrm{Pa}$ & $\tau_{i} / \mathrm{s}$ \\
\hline
\end{tabular}

Maxwell modes

\begin{tabular}{llllll}
1 & 11.30 & 0.0013 & 1 & 10.83 & 0.0015 \\
2 & 3.51 & 0.0097 & 2 & 311 & 0.013 \\
3 & 0.931 & 0.0528 & 3 & 0.703 & 0.073 \\
4 & 0.116 & 0.287 & 4 & 0.067 & 0.439 \\
5 & 0.005 & 1.76 & 5 & 0.002 & 3.14 \\
\hline
\end{tabular}

Flow-induced crystallization

Figure 6 shows the evolution of $G^{\prime}$ without flow application for all grades at their specific crystallization temperature. Clear differences between the different materials are observed. The starting plateau is higher for increasing ethylene content. When a polymer melt is cooled down, the stiffness of the melt increases. Since the materials used show the same visco-elastic behavior and the crystallization experiments are performed at lower temperatures for the copolymers, the melt stiffness and thus the starting plateaus are higher. The horizontal shift factors, $a_{T}$ (Table 3 ), at their respective $T_{\text {exp }}$, calculated using the Arrhenius equation and normalized to $a_{T}$ of the homopolymer, are 1, 1.4, 2.1, and 2.3 for the homopolymer PP and copolymers RACO1, RACO2, and RACO3, respectively. This corresponds well to the rise in starting plateau which increases by a factor 1.4 (RACO1), 1.9 (RACO2), and 2.1 (RACO3) compared to that of PP. The end levels of the storage moduli decrease with increasing ethylene content, which is correlated to the crystallinity values determined from DSC.

At equal nominal undercooling, crystallization is faster with increasing amount of ethylene monomers. The transition half-time, $t_{1 / 2}$, the time at which the half change of the viscoelastic functions occur, is defined as a characteristic time scale of the process. To determine $t_{1 / 2}$, the $G^{\prime}$ data are converted to space filling, $\varphi$ (ranging from 0 to 1 ). Khanna [56] defined $\varphi$ as:

$\varphi=\frac{G^{\prime}-G_{0}^{\prime}}{G_{\infty}^{\prime}-G_{0}^{\prime}}$

with $\mathrm{G}_{0}^{\prime}$ and $\mathrm{G}^{\prime}{ }_{\infty}$ the values of the start and end plateau respectively. Pogodina et al. [57] normalized the storage modulus by:

$\varphi=\frac{\log \left(G^{\prime} / G_{0}^{\prime}\right)}{\log \left(G_{\infty}^{\prime} / G_{0}^{\prime}\right)}=\frac{\log G^{\prime}-\log G_{0}^{\prime}}{\log G_{\infty}^{\prime}-\log G_{0}^{\prime}}$

When $\varphi$, determined from optical microscopy, is plotted versus the log of time, S-shaped curves similar to those in Figs. 6 and 7 are obtained [35]. Although Eq. 10 is too simple to accurately estimate the degree of space filling and a more advanced suspension modeling is needed to derive the proper $\varphi$, the time scales obtained are similar. The end plateau shows a slight but steady increase, which makes a consistent determination of $G_{\infty}^{\prime}$ problematic. Here, it is defined as the intercept of the tangents drawn along the end plateau and the regime of maximum changes (Fig. 6). The homopolymer and RACO3 have a $t_{1 / 2}$ of 7,300 and $1,100 \mathrm{~s}$, respectively, giving a ratio of 6.6. The often used Avrami equation describes $\varphi$ in case of 


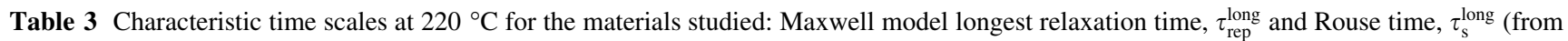
Eq. 4)

\begin{tabular}{lllllll}
\hline & $\tau_{\text {rep }}^{\text {long }} / \mathrm{s}$ & $\tau_{\mathrm{s}}^{\text {long }} / \mathrm{s}$ & $T_{\text {exp }}{ }^{\circ} \mathrm{C}$ & $a_{T}$ & $\tau_{\text {rep }}^{\text {long }}\left(T_{\exp }\right) / \mathrm{s}$ & $\tau_{\mathrm{s}}^{\text {long }}\left(T_{\text {exp }}\right) / \mathrm{s}$ \\
\hline PP & 1.46 & $8.11 \times 10^{-3}$ & 138 & 8.11 & 11.84 & $6.58 \times 10^{-2}$ \\
RACO1 & 2.07 & $1.15 \times 10^{-2}$ & 126 & 11.20 & 23.18 & $1.29 \times 10^{-1}$ \\
RACO2 & 1.76 & $9.78 \times 10^{-3}$ & 119 & 16.61 & 29.23 & $1.62 \times 10^{-1}$ \\
RACO3 & 3.14 & $1.74 \times 10^{-2}$ & 117 & 18.39 & 57.74 & $3.21 \times 10^{-1}$ \\
\hline
\end{tabular}

Temperature at which the FIC experiments are performed, $T_{\exp }$, the corresponding temperature shift factor, $a_{T}$, and the relaxation times, $\tau_{\text {rep }}^{\text {long }}\left(T_{\text {exp }}\right)$ and $\tau_{\mathrm{s}}^{\text {long }}\left(T_{\text {exp }}\right)$, respectively

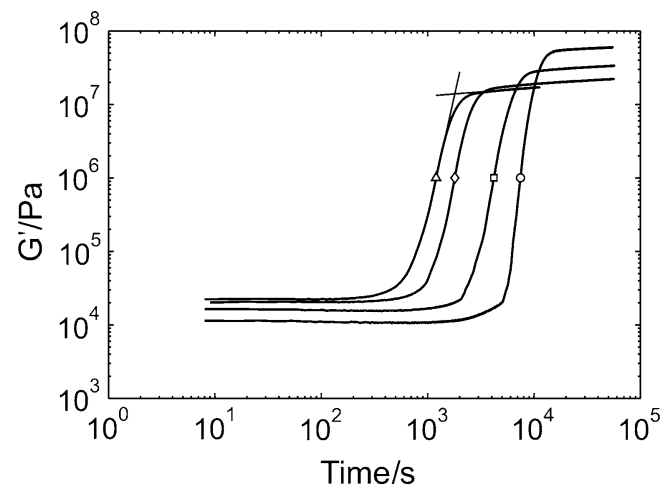

Fig. 6 Time build-up of the storage modulus under quiescent conditions at assumed equal undercooling for the homopolymer PP (open circle) and the copolymers RACO1 (open square), RACO2 (open diamond) and RACO3 (open triangle)

isothermal crystallization, for which all nuclei $N$ appear at the same time $t_{0}$, and the growth rate $G$ is constant in time:

$\varphi=1-\exp \left[-\frac{4}{3} \pi N G^{3}\left(t-t_{0}\right)^{3}\right]$

Gahleitner et al. [29] determined $N$ and $G$ from thin slice experiments over a temperature between 80 and $120^{\circ} \mathrm{C}$. At all temperatures, a factor of 4 difference between the growth rate of $\mathrm{PP}$ (high $G$ ) and $\mathrm{RACO} 3$ (low $G$ ) was found. The growth rates of RACO1 and RACO2 are in between the two extremes. At their experimental crystallization temperatures, the difference in number of nuclei for PP and RACO3 is a factor $10\left(\sim 10^{12.5}\right.$ and $\sim 10^{13.5} \mathrm{~m}^{-3}$, respectively) and the difference in growth rate is a factor 3 ( $\sim 10^{-7.5}$ and $\sim 10^{-7} \mathrm{~m} \mathrm{~s}^{-1}$, respectively). From Eq. 11 the ratio of $t_{1 / 2}$ between the two materials can be derived, using $\varphi=0.5$, and is equal to

$\frac{t_{1 / 2, \mathrm{PP}}}{t_{1 / 2, \mathrm{RACO} 3}}=\sqrt[3]{\frac{\left(N G^{3}\right)_{\mathrm{RACO} 3}}{\left(N G^{3}\right)_{\mathrm{PP}}}}$

With the values found for $N$ and $G$ the ratio is 6.8 , which is very similar to the measured value.

Short-term shear flow experiments are performed at different shear rates applying a constant macroscopic strain
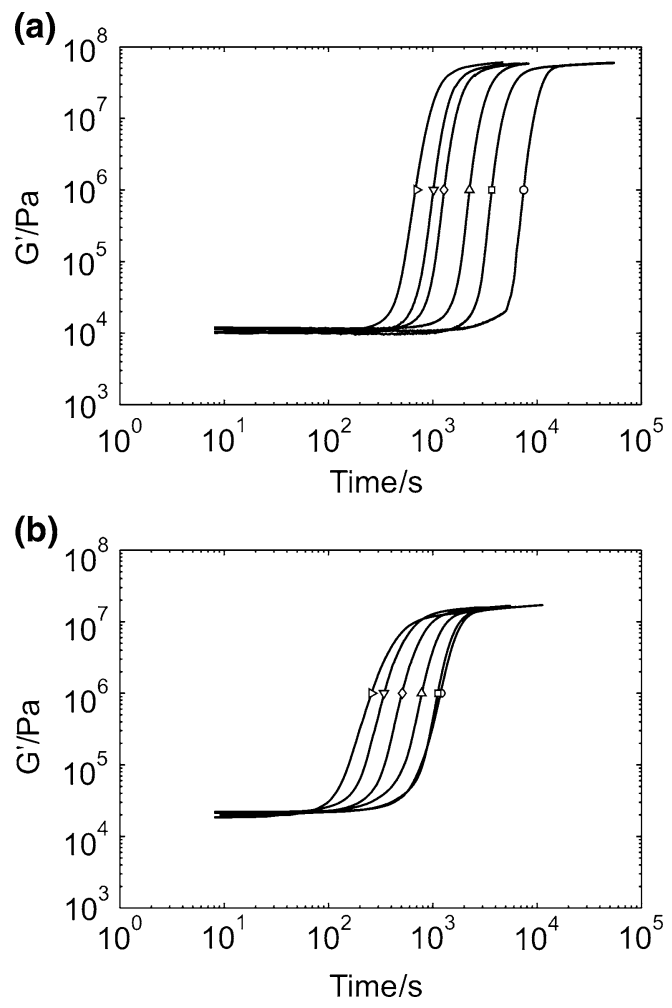

Fig. 7 Time build-up of the storage modulus for the homopolymer $\mathrm{PP}$ at $138{ }^{\circ} \mathrm{C}$ a and the RACO 3 at $117{ }^{\circ} \mathrm{C} \mathbf{b}$ under quiescent conditions (open circle) and after application of flow: $3 \mathrm{~s}^{-1}$ for $20 \mathrm{~s}$ (open square), $6 \mathrm{~s}^{-1}$ for $10 \mathrm{~s}$ (open triangle), $15 \mathrm{~s}^{-1}$ for $4 \mathrm{~s}$ (open diamond), $30 \mathrm{~s}^{-1}$ for $2 \mathrm{~s}$ (open inverted triangle) and $60 \mathrm{~s}^{-1}$ for $1 \mathrm{~s}$ (open slanting triangle)

$(\gamma=60)$ before monitoring crystallization. Results for the homopolymer and RACO3, the random copolymer with the highest ethylene content, together with those of crystallization under quiescent conditions, are shown in Fig. 7. Applying a shear flow accelerates the crystallization process. For both materials, it is observed that there is no change in the initial $G^{\prime}$. With increasing shear rate, the build-up of $G^{\prime}$ starts at earlier times, but the slope with which $G^{\prime}$ rises remains the same, i.e., the kinetics of the process are not altered. The effectiveness of flow is more 
pronounced for the homopolymer than for the copolymer, RACO3, where the evolution of $G^{\prime}$ for the lowest shear rate $\left(\dot{\gamma}=3 \mathrm{~s}^{-1}\right)$ is almost equal to the quiescent result. Apparently, a critical shear rate exists (at a constant macroscopic strain level) below which flow does not speed up the crystallization process. The effectiveness of flow can be quantified by defining a dimensionless crystallization halftime $\Theta$ as [47]:

$\Theta=\frac{t_{1 / 2, \dot{\gamma}}}{t_{1 / 2, Q}}$

The FIC experiments are indicated by $\dot{\gamma}$, the $Q$ indicates the half-time for quiescent conditions.

Figure 8 shows the dimensionless crystallization halftime, $\Theta$, as a function of shear rate, for the condition that the macroscopic applied shear strain is constant $(\gamma=60)$. It shows that, under these conditions, there is a transition to morphology type 2 in which the flow is strong enough to accelerate the crystallization process. No change in crystallization kinetics is observed (Fig. 7), and hence, only the number of point nuclei is increased. Morphology type 2 starts at a critical shear rate, $\dot{\gamma}_{c}$, above which the step shear influences the crystallization kinetics. With increasing ethylene content, $\dot{\gamma}_{c}$ shifts toward higher values. For RACO3, the lowest applied shear rate of $\dot{\gamma}=3 \mathrm{~s}^{-1}$ is very close to $\dot{\gamma}_{c}$, which is a factor 4 higher than that of the homopolymer $\left(\sim 0.7 \mathrm{~s}^{-1}\right)$. For all 4 grades, the onset of this regime, i.e., the critical shear rate, falls within flow regime II, but it does not coincide with the transition between flow regime I and II, given by $\dot{\gamma}=1 / \tau_{\text {rep }}^{\text {long }}$ (Table 3). Furthermore, no transition to morphology type 3 , where fibrillar structures form, is observed. An exception in this picture is RACO2 which is influenced more by flow than the homopolymer, i.e., $\dot{\gamma}_{c}$ shifts to a lower value, due to the presence of the silica anti-blocking agent. When flow

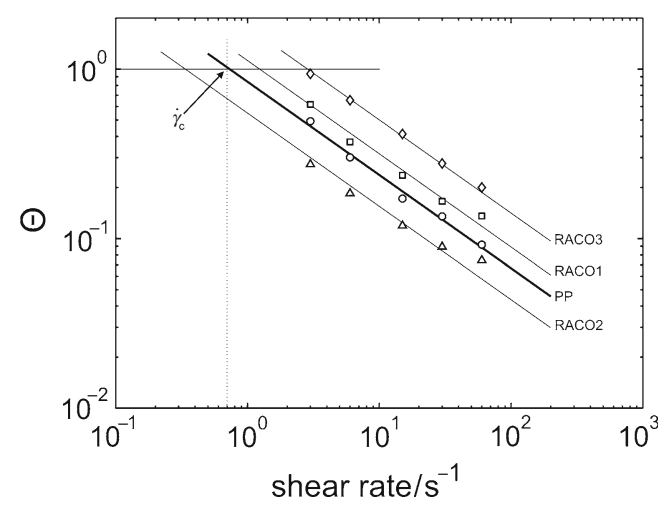

Fig. 8 Dimensionless crystallization half-time $\Theta$ obtained from dynamical mechanical experiments for PP (open circle), RACO1 (open square), RACO2 (open triangle) and RACO3 (open diamond) as a function of shear rate $\dot{\gamma}$ applied during the pre-shear condition with the macroscopic strain, $\gamma=60$. The critical shear rate $\dot{\gamma}_{c}$ for PP is indicated with the dotted line is applied, the presence of these particles constituting the additives locally increases the velocity gradients [21]. As such, fillers increase the influence of flow on crystallization and crystal orientation [19], and alter mechanical properties [16]. An indication for the increased effective stretching is hard to obtain, since these particles show a large distribution of size $(100 \mathrm{~nm}-10 \mu \mathrm{m})$ and shape differences (spherical and plate-like), which should be taken into account in the modeling. It has to be noticed that the quiescent experiments are not influenced by the presence of the particles, i.e., no extra nucleation effect is observed, both in the DSC measurements, which would show an increase in $T_{\mathrm{c}}$ (Fig. 4) and in the quiescent rheometry measurements (Fig. 6).

The minimum $\dot{\gamma}$ for chain stretching for PP is calculated to be $15 \mathrm{~s}^{-1}\left(D e_{\mathrm{s}}=1\right)$. However, for shear rates (equal and) higher than this critical value $\left(15,30\right.$, and $\left.60 \mathrm{~s}^{-1}\right)$, no transition toward morphology type 3 is observed. The pre-shear conditions that fulfill $D e_{\mathrm{s}}>1$, i.e., deformations strong enough to stretch the molecules and enter the fibrillar regime are not the sole requirement for a change in the crystallization kinetics [15]. The duration of the flow also plays an important role. It is necessary to reach a characteristic strain at which a transition from one to the other regime is observed. This is demonstrated in Fig. 9. Figure 9a to c show FIC experiments with a shear rate of 3,15 , and $60 \mathrm{~s}^{-1}$, respectively, with increasing shear time such that the total shear strain applied is constant for all shear rates applied and equals to 60,120 , and 240. In all figures, the quiescent case is included as well. For the low shear rates (up to $15 \mathrm{~s}^{-1}$ ), no change in crystallization kinetics is observed, only an effect in the onset time of crystallization (Fig. 9a, b). Above a shear rate of $15 \mathrm{~s}^{-1}$, Fig. 9c, the time evolution of the viscoelastic properties is changed. First, an initial increase of $G^{\prime}$ indicates the formation of some initial structure in the melt during flow and secondly, the slope of the $G^{\prime}$-evolution curve is altered. For the three strain levels, the dimensionless crystallization half-time $\Theta$ is displayed in Fig. 9d. It is shown that with an increasing $\gamma$, the critical shear rate at which flow starts to effect the crystallization process shifts to lower values. For the highest strain level $\dot{\gamma}_{c}=0.3 \mathrm{~s}^{-1}$, which is close to the transition from flow regime I to II, determined from the condition $D e_{\text {rep }}=1$ to be $0.09 \mathrm{~s}^{-1}$ based on the longest chains $\left(\tau_{\text {rep }}^{\text {long }}\right)$. Furthermore, for the high strain level of 240, the slope of $\Theta$ versus $\dot{\gamma}$ changes around a shear rate of $15 \mathrm{~s}^{-1}$, which is the lowest shear rate that can possibly stretch the polymer chains according to $D e_{\mathrm{s}}>1-10$. Higher strain levels can not be reached because of arising problems like edge fracture and material loss, i.e., polymer flowing outside the plates.

The results shown in Fig. 8 have a total macroscopic strain of 60 as a pre-shear condition at equal undercooling. The flow strength experienced by the molecules, i.e., the 
Fig. 9 Time build-up of the storage modulus for the homopolymer PP at $138{ }^{\circ} \mathrm{C}$ after application of flow at different shear rates: $\mathbf{a} \dot{\gamma}=3 \mathrm{~s}^{-1}$, b $\dot{\gamma}=15 \mathrm{~s}^{-1}, \mathbf{c} \dot{\gamma}=60 \mathrm{~s}^{-1}$, and different strains; quiescent conditions (open circle), FIC with $\gamma=60$ (open square), $\gamma=120$ (open triangle), and $\gamma=240$ (open diamond).

d Dimensionless crystallization half-time, $\Theta$, versus $\dot{\gamma}$ for the three different levels of shear strain, symbols are as in $(\mathbf{a}-\mathbf{c})$

(a)

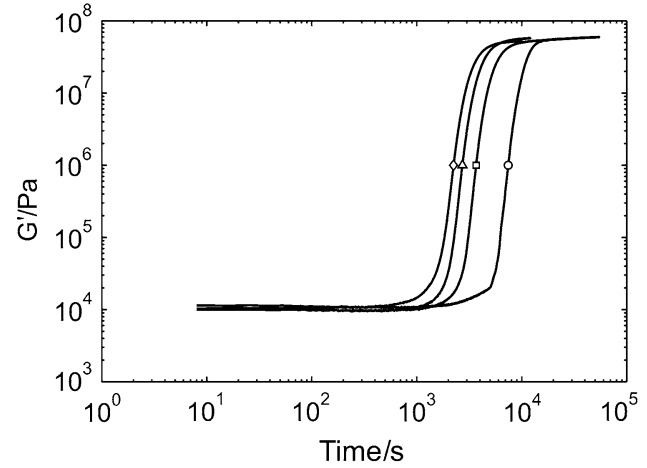

(c)

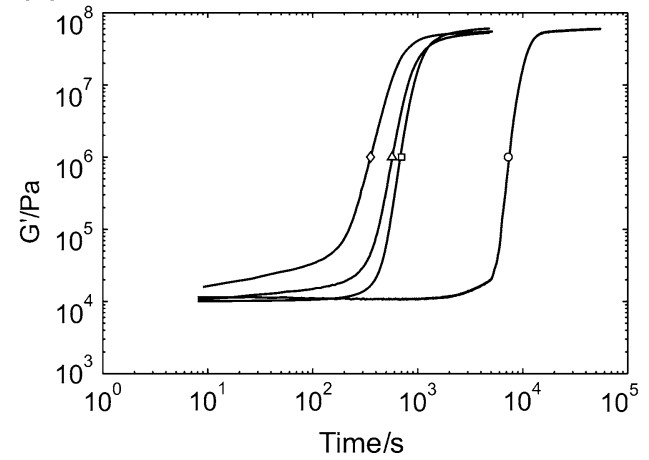

(b)

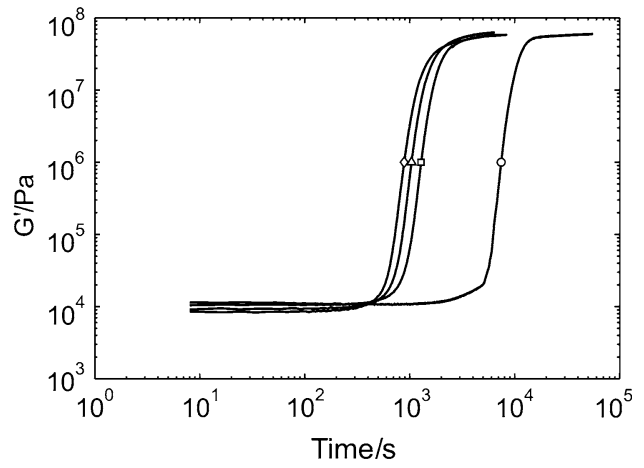

(d)

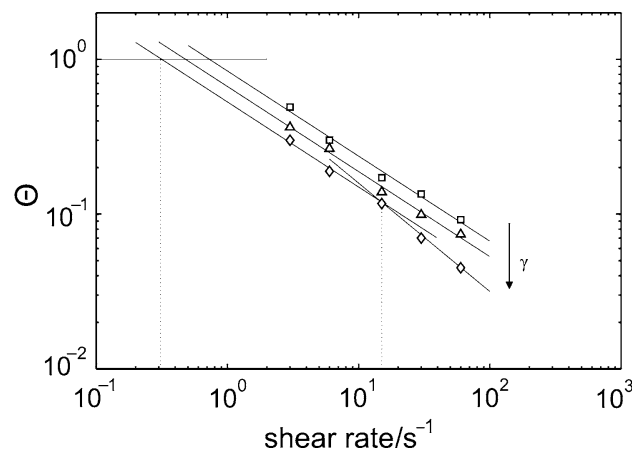

molecular strain, is however not of the same level. The molecular strain is the driving force for flow enhanced nucleation and crystallization $[44,58]$. This implies that the molecular strain, and thus the driving force, experienced by the homopolymer is lowest and increases for the RACO grades because of the decreased $T_{\text {exp }}$. A better comparison would therefore be to apply pre-shear conditions with the same molecular strain. To achieve equal molecular strain levels, the Deborah number for the FIC experiments has to be the same. The Deborah numbers for PP corresponding to the measurements in Fig. 7 are reported in Table 4 using $\tau_{\text {rep }}^{\text {long }}$ as the characteristic time scale. To achieve the same molecular strain for the RACO grades either $T_{\text {exp }}$ or $\dot{\gamma}$ has to be altered. Since $T_{\text {exp }}$ is already fixed from the requirement that the undercooling is constant, $\dot{\gamma}$ will be changed. The $\dot{\gamma}$ values are listed in Table 4 .

Table 4 Deborah numbers determined from the applied pre-shear conditions $(\gamma=60)$ for PP (using $a_{T}$ and $\tau_{\text {rep }}^{\text {long from Table } 3) \text { and }}$ corresponding shear rates for the three RACO material grades

\begin{tabular}{lcccc}
\hline De & $\dot{\gamma} / \mathrm{s}^{-1}$ & & & \\
\cline { 2 - 5 } & PP & RACO1 & RACO2 & RACO3 \\
\hline 36 & 3 & 1.5 & 1.2 & 0.6 \\
71 & 6 & 3.1 & 2.4 & 1.2 \\
178 & 15 & 7.7 & 6.1 & 3.1 \\
355 & 30 & 15.3 & 12.2 & 6.2 \\
710 & 60 & 30.6 & 24.3 & 12.3 \\
\hline
\end{tabular}

Figure 10 shows $\Theta$ as a function of the Deborah number for orientation, $D e_{\text {rep }}$, at constant strain within one grade, thus keeping the product $D e_{\text {rep }} t_{\mathrm{s}}$ constant for all grades. It shows that a critical Deborah number, $D e_{\mathrm{c}}$, is necessary to influence the crystallization kinetics. This is most clearly demonstrated with the results of RACO3. Under these shear conditions, the differences between the grades become even more pronounced. The influence of filler particles in RACO2 is still present, i.e., the curve is shifted to the left (lower $D e$ ) compared to RACO1, but, in this case, the flow has more effect on the crystallization of pure PP.

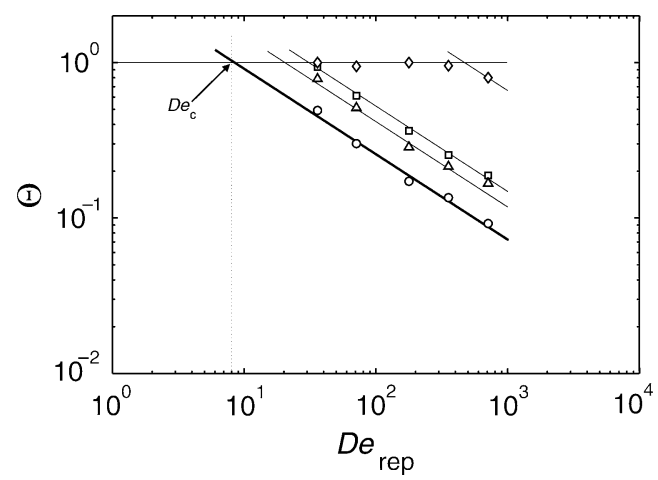

Fig. 10 Dimensionless crystallization half-time, $\Theta$, obtained from dynamical mechanical experiments for PP (open circle), RACO1 (open square), RACO2 (open diamond), and RACO3 (open diamond) as a function of Deborah number related to molecular orientation, $D e_{\text {rep }}$, applied during the pre-shear condition. The critical Deborah number, $D e_{\mathrm{c}}$, for PP, is indicated with the dotted line 


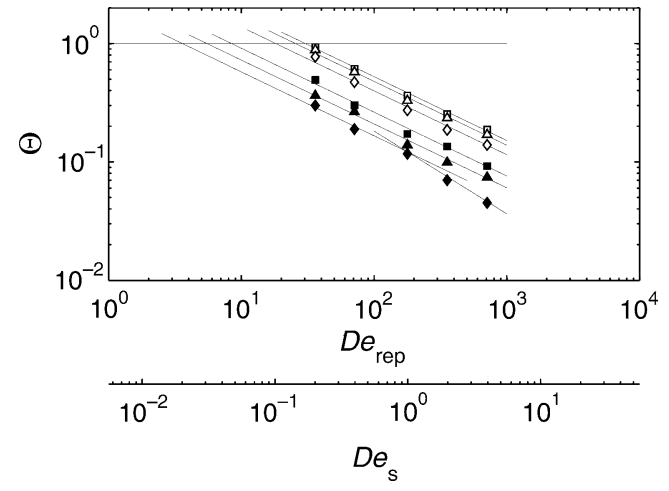

Fig. 11 Dimensionless crystallization half-time, $\Theta$, obtained from dynamical mechanical experiments for PP (closed symbols) and RACO1 (open symbols) as a function of Deborah number, $D e$, with the pre-shear conditions $D e_{\text {rep }} t_{\mathrm{s}}=710$ (open squarelfilled square), $D e_{\text {rep }} t_{\mathrm{s}}=1,420$ (open trianglelfilled triangle) and $D e_{\text {rep }} t_{\mathrm{s}}=2840$ (open diamondlfilled triangle)

To show, once more, the importance of shear time, experiments at different levels of strain are performed and the effect is shown in Fig. 11 for PP and RACO1. For the same conditions applied, i.e., De $t_{\mathrm{s}}=$ constant, the behavior of the grades is not identical and the onset of morphology type 2 occurs at different values of $D e$. Furthermore, where PP forms shish-kebab structures for the strongest flow conditions (morphology type 3), RACO1 is still in morphology type 2 . So, although different morphology types exist for all grades, the transitions between the regimes are specific for every grade, under the same flow conditions applied.

\section{Conclusions}

- The presence of ethylene co-monomers does not change the linear visco-elastic behavior of iPP.

- At equal nominal undercooling, the rate of crystallization increases with increasing amount of ethylene.

- At a given shear rate, keeping the total macroscopic strain applied constant $(\gamma=60)$, the effect on the crystallization rate decreases with increasing ethylene content. The difference between the grades is even more pronounced at equal levels of molecular deformation, i.e., $D e$ is constant.

- For the homopolymer it is shown that, in accordance with van Meerveld et al. [15], a change in the crystallization kinetics, i.e., a transition from isotropic toward oriented structures, occurs when the HMW chains are subjected to the condition $D e_{\mathrm{s}}>1$, based on $\tau_{\mathrm{s}}^{\text {long }}$ for a sufficiently long time.

- Although the different morphology types exist, the transitions between the regimes are specific for every grade, under the same flow conditions applied.
Acknowledgements This work is part of the Research Programme of the Dutch Polymer Institute (DPI), PO Box 902, 5600 AX Eindhoven, The Netherlands, projectnr. \#454.

Open Access This article is distributed under the terms of the Creative Commons Attribution Noncommercial License which permits any noncommercial use, distribution, and reproduction in any medium, provided the original author(s) and source are credited.

\section{References}

1. Schrauwen BAG, van Breemen LCA, Spoelstra AB, Govaert LE, Peters GWM, Meijer HEH. Structure, deformation and failure of flow-oriented semi-crystalline polymers. Macromolecules. 2004;39:8618-33.

2. Schrauwen BAG. Deformation and failure of semi-crystalline polymer systems. PhD-thesis, Eindhoven University of Technology, The Netherlands; 2003.

3. Kalay G, Sous RA, Reis RL, Cunha AM, Bevis MJ. The enhancement of the mechanical properties of a high-density polyethylene. J Appl Polym Sci. 1999;73:2473-83.

4. Zuidema H. Flow induced crystallization of polymers. PhD-thesis, Eindhoven University of Technology, The Netherlands, 2000.

5. Kristiansen M, Werner M, Tervoort T, Smith P, Blomenhofer M, Schmidt H-W. The binary system isotactic polypropylene/bis(3, 4-dimethylbenzylidene)sorbitol: phase behavior, nucleation, and optical properties. Macromolecules. 2003;36:5150-6.

6. Vleeshouwers S, Meijer HEH. A rheological study of shear induced crystallization. Rheol Acta. 1996;35:391-9.

7. Vega JF, Hristova DG, Peters GWM. Flow-induced crystallization regimes and rheology of isotactic polypropylene: effects of molecular architecture. J Therm Anal Calorim. 2009; doi: 10.1007/s10973-009-0516-3.

8. Liedauer S, Eder G, Janeschitz-Kriegl H, Jerschow P, Geymayer $\mathrm{W}$, Ingolic E. On the kinetics of shear-induced crystallization of polypropylene. Int Polym Proccess 1993;8:236-50.

9. Kumaraswamy G, Issaian AM, Kornfield JA. Shear-enhanced crystallization in isotactic polypropylene. 1. Correspondence between in situ rheo-optics and ex situ structure determination. Macromolecules. 1999;32:7537-47.

10. Kumuraswamy G, Verma RK, Issaian AM, Wang P, Kornfield JA, Yeh F, et al. Shear-enhanced crystallization in isotactic polypropylene. Part 2. Analysis of the formation of the oriented "skin". Polymer. 2000;41:8931-40.

11. Somani RH, Hsiao BS, Nogales A, Srinivas S, Tsou AH, Sics I, et al. Structure development during shear flow-induced crystallization of i-PP: in-situ small-angle X-ray scattering study. Macromolecules. 2000;33:9385-94.

12. Seki M, Thurman DW, Oberhauser JP, Kornfield JA. Shearmediated crystallization of isotactic polypropylene: the role of long chain-long chain overlap. Macromolecules. 2002;35: 2583-94.

13. Baert J, Van Puyvelde P. Effect of molecular and processing parameters on the flow-induced crystallization of poly-1-butene. Part 1: kinetics and morphology. Polymer. 2006;47:5871-9.

14. Baert J, Van Puyvelde P, Langouche F. Flow-induced crystallization of PB-1: from the low shear rate region up to processing rates. Macromolecules. 2006;39:9215-22.

15. van Meerveld J, Peters GWM, Hütter M. Towards a rheological classification of flow induced crystallization experiments of polymer melts. Rheol Acta. 2004;44:119-34.

16. Schrauwen BAG, Govaert LE, Peters GWM, Meijer HEH. The influence of flow-induced crystallization on the impact toughness 
of high-density polyethylene. Macromol Symp. 2002;185: 89-102.

17. Muratoglu OK, Argon AS, Cohen RE, Weinberg M. Toughening mechanism of rubber-modified polyamides. Polymer. 1995;36:921-30.

18. Ergungor Z, Cakmak M, Batur C. Effect of processing conditions on the development of morphology in clay nanoparticle filled nylon 6 fibers. Macromol Symp. 2002;185:259-76.

19. Yalcin B, Valladares D, Cakmak M. Amplification effect of platelet type nanoparticles on the orientation behavior of injection molded nylon 6 composites. Polymer. 2003;44:6913-25.

20. Yalcin B, Cakmak M. Superstructural hierarchy developed in coupled high shear/high thermal gradient conditions of injection molding in nylon 6 nanocomposites. Polymer. 2004;45:2691-710.

21. Hwang WR, Peters GWM, Hulsen MA, Meijer HEH. Flowinduced crystallization of particle-filled polymers. Macromolecules. 2006;39:8389-98.

22. Fillon B, Lotz B, Thierry A, Wittmann JC. Self-nucleation and enhanced nucleation of polymers. Definition of a convenient calorimetric "efficiency scale" and evaluation of nucleating additives in isotactic polypropylene ( $\alpha$ phase). J Polym Sci B. 1993;31:1395-405.

23. Kristiansen M, Tervoort T, Smith P, Goossens H. Mechanical properties of sorbitol-clarified isotactic polypropylene: influence of additive concentration on polymer structure and yield behavior. Macromolecules. 2005;38:10461-5.

24. Balzano L, Rastogi S, Peters GWM. Flow induced crystallization in iPP-DMDBS blends: implications on morphology of shear ad phase separation. Macromolecules. 2008;41:399-408.

25. Balzano L, Portale G, Peters GWM, Rastogi S. Thermo-reversible DMDBS phase separation in iPP: effects of flow induced crystallization. Macromolecules. 2008;41:5350-5.

26. Blomenhofer M, Ganzleben S, Hanft D, Schmidt H-W, Kristiansen M, Smith P, et al. "Designer" nucleating agents for polypropylene. Macromolecules. 2005;38:3688-95.

27. Kristiansen M. Nucleation and clarification of semi-crystalline polymers. PhD-Thesis, ETH Zürich; 2004.

28. Grein C. Toughness of neat, rubber modified and filled $\beta$-nucleated polypropylene: from fundamentals to applications. In: HH Kausch, editor. Advances in polymer science, intrinsic molecular mobility and toughness of polymers II. Berlin:Springer; 2005. pp. 43-104.

29. Gahleitner M, Jääskeläinen P, Ratajski E, Paulik C, Reussner J, Wolfschwenger J, et al. Propylene-ethylene random copolymers: comonomer effects on crystallinity and application properties. J Appl Polym Sci. 2005;95:1073-81.

30. Maspoch MLl, Gamez-Perez J, Gimenez E, Santana OO, Gordillo A. Influence of processing on ethylene-propylene block copolymers: structure and mechanical behavior. J Appl Polym Sci. 2004;93:2866-78.

31. Gamez-Perez J, Muñoz P, Santana OO, Gordillo A. Maspoch MLl. Influence of processing on ethylene propylene block copolymers (II): fracture behavior. J Appl Polym Sci. 2006;101:2714-24.

32. Resch K, Wallner GM, Teichert C, Maier G, Gahleitner M. Optical properties of highly transparent polypropylene cast films: influence of material structure, additives, and processing conditions. Polym Eng Sci. 2006;46:520-31.

33. Wallner GM, Resch K, Teichert C, Gahleitner M, Binder W. Effect of material structure and additives on the optical properties of $P P$ cast films. Monatshefte für Chemie. 2006;137:887-97.

34. Bu H-S, Cheng SZD, Wunderlich B. Addendum to the thermal properties of polypropylene. Makromol Chem Rapid Commun. 1988;9:75-7.

35. Steenbakkers RJA, Peters GWM. Suspension-based rheological modeling of crystallizing polymer melts. Rheol Acta. 2008;47:643-65.
36. Avrami M. Kinetics of phase change. I. General theory. J Chem Phys. 1939;7:1103-12.

37. Avrami M. Kinetics of phase change. II. Transformation-time relations for random distribution of nuclei. J Chem Phys. 1940;8:212-24.

38. Lamberti G. A direct way to determine iPP density nucleation from DSC isothermal measurements. Polym Bull. 2004;52:443-9.

39. Avila-Orta CA, Burger C, Somani R, Yang L, Marom G, Medellin-Rodriguez FJ, et al. Shear-induced crystallization of isotactic polypropylene within the oriented scaffold of noncrystalline ultrahigh molecular weight polyethylene. Polymer. 2005;46:8859-71.

40. Swartjes FHM. Stress induced crystallization in elongational flow. $\mathrm{PhD}$ thesis, Eindhoven University of Technology, The Netherlands; 2001.

41. Eder G, Janeschitz-Kriegl H. Crystallization. In: HEH Meijer, editor. Materials science and technology, vol 18: processing of polymers, chap. 5. Weinheim: VCH; 1997.

42. Koscher E, Fulchiron R. Influence of shear on polypropylene crystallization: morphology development and kinetics. Polymer. 2002;43:6931-42.

43. Vega JF, Rastogi S, Peters GWM, Meijer HEH. Rheology and reptation of linear polymers. Ultrahigh molecular weight chain dynamics in the melt. J Rheol. 2004;48:663-78.

44. Zuidema H, Peters GWM, Meijer HEH. Development and validation of a recoverable strain based model for flow-induced crystallization of polymers. Macromol Theor Simul. 2001;10:447-60.

45. Peters GWM, Swartjes FHM, Meijer HEH. A recoverable strain based model for flow-induced crystallization. Macromol Symp. 2002;185:277-92.

46. Custodio FJMF, Steenabkkers RJA, Anderson PD, Peters GWM, Meijer HEH. Model development and validation of crystallization behavior in injection molding prototype flows. Macromol. Theory Simul. 2009;doi:10.1002/mats.200900016

47. Acierno S, Palomba B, Winter HH, Grizzuti N. Effect of molecular weight on the flow-induced crystallization of isotactic poly(1-butene). Rheol Acta. 2003;42:243-50.

48. Coppola S, Balzano L, Gioffredi E, Maffettone PL, Grizzuti N. Effects of the degree of undercooling on flow induced crystallization in polymer melts. Polymer. 2004;45:3249-56.

49. Wunderlich B. Thermal analysis of polymeric materials. Berlin: Springer-Verlag; 2005.

50. Hoffman JD, Weeks JJ. J Res Nat Bur Stand. 1962;66A:13-28.

51. Xu J, Srinavas S, Marand H, Argawal P. Equilibrium melting temperature and undercooling dependence of the spherulitic growth rate of isotactic polypropylene. Macromolecules. 1998;31:8230-42.

52. Mezghani K, Anderson Campbell R, Phillips PJ. Lamellar thickening and the equilibrium melting point of polypropylene. Macromolecules. 1994;27:997-1002.

53. Mezghani K, Phillips PJ. $\gamma$-phase in propylene copolymers at atmospheric pressure. Polymer. 1995;36:2407-11.

54. Laihonen S, Gedde UW, Werner P-E, Matrinez-Salazar J. Crystallization kinetics and morphology of poly(propylene-stat-ethylene) fractions. Polymer. 1997;38:361-9.

55. Macosko CW. Rheology, principles, measurements and application. New York: Wiley-VCH; 1994.

56. Khanna YP. Rheological mechanism and overview of nucleated crystallization kinetics. Macromolecules. 1993;26:3639-43.

57. Pogodina NV, Winter HH, Srinivas S. Polypropylene crystallization as a physical gelation process. Macromolecules. 1999;31:8164-72.

58. McHugh AJ, Guy RK, Tree DA. Extensional flow-induced crystallization of a polyethylene melt. Colloid Polym Sci. 1993;271:629-45. 